\title{
Dual Effects of Exercise in Dysferlinopathy
}

\author{
Olivier Biondi, ${ }^{*}$ Marie Villemeur, ${ }^{*}$ Alice Marchand, ${ }^{*}$ Fabrice Chretien, ${ }^{*}$ Nathalie Bourg, ${ }^{\dagger}$ Romain K. Gherardi, ${ }^{* \ddagger}$ \\ Isabelle Richard, ${ }^{\dagger}$ and François-Jérôme Authier*
}

\begin{abstract}
From the Cellular Interactions in the Neuromuscular System Team,* INSERM U955-E 10, Université Paris Est-Creteil, Créteil; the Généthon-CNRS UMR8587 LAMBE, ${ }^{\dagger}$ Evry; and the Neuromuscular Diseases Reference Center Garches-Necker-Mondor-Hendaye, ${ }^{\ddagger}$ CHU Henri Mondor, APHP, Créteil, France
\end{abstract}

\author{
Accepted for publication \\ February 12, 2013. \\ Address correspondence to \\ F.J. Authier, M.D., Ph.D., \\ INSERM U955-E10, Faculté \\ de médecine de Créteil, 8, \\ rue du Général Sarrail, F94000 \\ Creteil, France. E-mail: \\ authier@u-pec.fr.
}

\begin{abstract}
Dysferlinopathy refers to a group of autosomal recessive muscular dystrophies due to mutations in the dysferlin gene causing deficiency of a membrane-bound protein crucially involved in plasma membrane repair. The condition is characterized by marked clinical heterogeneity, the different phenotypes/modes of presentation being unrelated to the genotype. For unknown reasons, patients are often remarkably active before the onset of symptoms. Dysferlin deficiency-related persistence of mechanically induced sarcolemma disruptions causes myofiber damage and necrosis. We postulate that limited myodamage may initially remain hidden with well-preserved resistance to physical strains. By subjecting dysferlin-deficient B6.A/J-Dysf $f^{\text {prmd }}$ mice to long-term swimming exercise, we observed that concentric/isometric strain improved muscle strength and alleviated muscular dystrophy by limiting the accumulation of membrane lesions. By contrast, eccentric strain induced by long-term running in a wheel worsened the dystrophic process. Myofiber damage induced by eccentric strain increased with age, reflecting the accumulation of non-necrotic membrane lesions up to a critical threshold. This phenomenon was modulated by daily spontaneous activity. Transposed to humans, our results may suggest that the past activity profile shapes the clinical phenotype of the myopathy and that patients with dysferlinopathy should likely benefit from concentric exercise-based physiotherapy. (Am J Pathol 2013, 182: 2298-2309; http://dx.doi.org/10.1016/j.ajpath.2013.02.045)
\end{abstract}

Dysferlin is a membrane-bound 230-kDa protein conspicuously found in skeletal muscle, heart, and placenta, and weakly expressed in brain, liver, lung, spleen, pancreas, kidney, and leukocytes. ${ }^{1-4}$ Dysferlinopathy is a term referring to a group of autosomal recessive muscular dystrophies due to mutations in the dysferlin gene with reduced or absent dysferlin protein in the sarcolemma. ${ }^{5}$ Mutations in the dysferlin gene $\left(D Y S F, M^{*}{ }^{*} 603009\right)^{1,6}$ were first identified in early adult-onset distal myopathy type II or Myoshi myopathy (MM), and limb-girdle muscle dystrophy 2B (LGMD2B). The clinical spectrum was extended with the recognition of other phenotypes, including those with unusual, early, ${ }^{7}$ and late $^{8}$ ages of onset; unusual proximodistal, ${ }^{9}$ axial, ${ }^{10}$ and distal anterior $^{11}$ topography of initial involvement; and presentation as pseudometabolic myopathy ${ }^{9}$ or as asymptomatic hyperCKemia. ${ }^{9,11,12}$ In addition, muscle inflammation is a relatively consistent finding, often mimicking inflammatory myopathy. ${ }^{13}$ However, genetic analysis failed to establish clear-cut genotype-phenotype correlations, and it became progressively clear that these phenotypes formed a range of symptoms of a single condition rather than distinct entities. Both MM and LGMD phenotypes were observed in different branches of the same family. ${ }^{12}$ Longitudinal evaluations showed topographical overlap, weakness progressively extending from proximal to distal muscle groups, or vice versa. ${ }^{8}$ Moreover, a recent study revealed strikingly similar muscular magnetic resonance imaging features at onset in MM and LGMD2B patients. ${ }^{14}$ If the initial splitting of dysferlinopathies into separate subtypes is progressively abandoned in favor of a single entity, the clinical heterogeneity of dysferlin myopathy is often challenging and remains unexplained so far.

Another distinctive feature of dysferlinopathy lies in the clinical course. Most muscular dystrophies are chronically

Supported by grants from the Association Française contre les Myopathies (AFM) (12549DdT1 to F.J.A. and I.R.), and from the Jain Foundation (I.R.). O.B. was a recipient of a post-doctoral fellowship from AFM (contract \# 13437).

Current address of O.B., Université Paris Descartes, UFR Biomédicale des Saints Pères, UMR 8194 CNRS, Paris, France. 
progressive. Therefore, when they appear in adulthood, patients may long remain minimally disabled. ${ }^{15}$ By contrast, adult onset of symptoms in dysferlinopathy is usually followed by rapid deterioration of muscle strength, leading to severe disability in just a few years. Moreover, during a varying period before onset, most patients have strictly normal, if not above-average, muscle strength, some being able to do sport at the top level or hold physically demanding jobs. ${ }^{16}$ These poorly understood clinical peculiarities should directly relate to the changes induced by the lack of normal dysferlin.

In contrast to dystrophin/glycoprotein complex-linked muscular dystrophies, dysferlin-null mice have structurally stable sarcolemma. ${ }^{17,18}$ However, electron microscopy studies in both human dysferlinopathy ${ }^{19}$ and dysferlin-null mice ${ }^{18}$ showed abnormalities in the sarcolemma, consisting of persistent breaches associated with basal lamina thickening and an underlying accumulation of small vesicles indicating impaired plasma membrane repair. Ex vivo studies confirmed that dysferlin deficiency is associated with the inability to repair focally injured plasma membrane, ${ }^{17,18}$ a crucial function for cell survival. ${ }^{20-22}$ Dysferlin-deficient myofibers show resistance to physical strain similar to normal myofibers. ${ }^{18}$ However, the persistence of sarcolemma disruptions may elicit danger signal delivery and extensive inflammation, ${ }^{13,23}$ with an amplification loop leading to myofiber damage and necrosis.

Repeated muscle contractions physiologically induce myofiber membrane damage that is quickly repaired by a dysferlindependent mechanism. Membrane damage is more frequently observed and more severe following eccentric/lengthening contractions compared to isometric or concentric/shortening contractions. ${ }^{24}$ Herein, we used dysferlin-deficient mice to examine whether the effects of exercise on muscle integrity and function could depend on its eccentric component and intensity; and if the muscle adaptation induced by physical training avoiding myofiber membrane damage could modulate the dystrophic process. We provide first evidence that exercise elicits extensive myoinjury in an age-related manner and determines its distribution, whereas noneccentric exercise improves muscle strength and limits myopathy progression in dysferlin-deficient mice. In addition, dysferlin-deficient myofiber sensitivity to eccentric contractions increased with age, suggesting a time-dependent accumulation of unrepaired membrane lesions necessary to reach a critical threshold.

Transposed in a clinical context, our results enlighten the pathophysiology of human dysferlinopathy and suggest that concentric exercise-based physiotherapeutic approaches could be promising for patient care.

\section{Materials and Methods}

\section{Animals and Exercise}

B6.A/J-Dysf $f^{\text {prmd }}$ (Bl.A/J) dysferlin-deficient mice were generated by back crossing $\mathrm{A} / \mathrm{J}$ dysferlin-deficient mouse in C57 BL/6 strain for four generations (I.R., Genethon, Evry, France). ${ }^{25}$ Only the dysferlin mutation was used to select littermates for the next generation, and we obtained Bl.A/J mice that were devoid of the A/J C5 complement mutation. Seventy-eight C57 BL/6 (C57; Janvier, Le Genest-SaintIsle, France) control mice, $36 \mathrm{~A} / \mathrm{J}$ (A/J; Jackson Laboratory, Bar Harbor, ME) and $70 \mathrm{Bl}$.A/J dysferlin-deficient mice were housed in the same conditions (two animals/ cage, same diet, food, and water ad libitum) to limit interindividual variability due to external effects on progression of disease. Animal care followed the national guidelines (Ministère de la Recherche et de la Technologie, France) for the detention, use, and ethical treatment of laboratory animals.

We designed new and innovative exercise protocols to subject mice to opposite muscle strain. The running-based protocol was done using a forced rodent wheel (TSE System, Bad Homburg, Germany) for 30 minutes at a speed of $14 \mathrm{~m} \cdot \min ^{-1}$. The swimming-based protocol used an adjustable-flow swimming pool (Charbonnier and Soude, 2006, Patent FR 06 53772), as previously described ${ }^{26}$ for 30 minutes, using a $5 \mathrm{~L} \cdot \min ^{-1}$ water flow.

For the analysis of chronic effect of exercise, control and dysferlin-deficient mice were subjected to a 1 month exercise period, 5 days per week and one bout per day. Mice were divided into two exercise groups, ie, 1 month chronic running (Chron-Run) and 1 month chronic swimming (Chron-Swim) mice, which were compared to 1 month resting mice (Rest) composed of a mix of mice put in the wheel without rotation or in the swimming pool without flow, to ensure optimum control of stress and confounding factors effects, as previously described. ${ }^{26}$ All chronic exercises were conducted in 3-month-old animals.

To analyze the effects of a single exercise, control and Bl.A/J mice were subjected to a unique bout of running (Oneoff Run) or swimming (One-off Swim) for 30 minutes at $14 \mathrm{~m} \cdot \mathrm{min}^{-1}$ speed and $5 \mathrm{~L} \cdot \min ^{-1}$ water flow, respectively. One- and 3-month-old mice were divided into six different groups, ie, before exercise (D + 0); and 1, 3, 5, 10, and 20 days after exercise $(\mathrm{D}+1 ; \mathrm{D}+3 ; \mathrm{D}+5 ; \mathrm{D}+10 ; \mathrm{D}+20)$.

\section{Kinematics Analysis}

Mice limbs were tagged with white markers at each joint, ie, forelimb: paw, elbow, and shoulder; hindlimb: paw, ankle, knee, and hip. Mice were then subjected to the same protocols of running-based or swimming-based exercises that were described above $\left(14 \mathrm{~m} \cdot \mathrm{min}^{-1}\right.$ in forced rodent wheel or $5 \mathrm{~L} \cdot \mathrm{min}^{-1}$ water flow for 30 minutes). At time 1,15 , and 30 minutes of exercise, mice were filmed in a lateral view for 60 seconds per movie, using a high-speed MemView digital video camera at 120 frames per second (Southern Vision System, SVSI, Madison, AL). The hindlimb and forelimb motion was then tracked by contrast using the Video Spot Tracker v05.07 software (National Institute of Biomedical Imaging and Bioengineering, National Institutes of Health, Bethesda, MD). The video analysis of the step and swimming cycles was performed offline using a single-step video (frame 
by frame). A step cycle was divided into two phases: a support phase (SP), defined as the interval from the initial frame of the foot contact to the frame when the foot leaves the ground, and a return phase, defined as the return of the foot in contact, as described. ${ }^{27} \mathrm{~A}$ swimming cycle was divided into two phases: a power stroke (PS) associated with the extension of the limb from minimum to maximum hip angle, and the return stroke associated with the flexion of the limb from hip maximum to minimum, as described. ${ }^{27}$ For the measurement of movement frequency, the time taken to complete one step of the swimming cycle was measured for each mouse. This measurement was randomly repeated 30 times during the three video recordings of each mouse. The movement amplitude during the running-based exercise was computed on the support phase. The Video Spot Tracker software provided distances that were calibrated against a $1-\mathrm{cm}$ marker put on the wheel or the glass of the swimming pool in all movies. The amplitude of movement during the swimmingbased training was computed on the power stroke. The parameters were calculated using MATLAB software R2011a v7.12.0.635 (MathWorks, Natick, MA) in an automatic program applied to all tracking.

The angle of steps and strokes were calculated 30 times per movie with the Image-Pro Plus software v6.0 (Media Cybernetics, Silver Spring, MD), between the horizontal line of the frame or the water surface and the anteroposterior axis of the mice.

\section{Behavioral Testing}

The grip strength was measured using a grip force tensiometer (Bioseb, Vitrolles, France) according to the TREATNMD guidelines. Forelimbs and four-limb traction strength tests were separately measured using a single thin metal rod and a thin metal grid, respectively, interfaced with a tensiometer. Mice gripped the metal rod with forelimbs or the metal grid with four limbs and the manipulator pulled it progressively by the tail along the instrument axis (following the manufacturer's protocol). Only the maximum value of five successive tries was retained as maximum force for each mouse, and the measurement was given in grams. The hindlimb grip strength was calculated by subtracting forelimbs from four-limb grip measurements.

Mice spontaneous activity was evaluated using an openfield test (exploratory test) and a locomotor activity test (ambulatory test). The open-field test used a wooden box measuring $28 \times 28 \times 10 \mathrm{~cm}$ divided into $167 \times 7-\mathrm{cm}$ squares, allowing comparisons of behavior and stress measurements as important markers of exercise conditions. The squares that were immediately adjacent to the walls were referred to as the periphery and the four remaining central squares were referred to as the center. The mice were tested individually, and the open field was washed after each session. Each mouse initially placed in the center of the open field was allowed to move freely for 5 minutes, during which time the number of both peripheral and central square crossings were manually recorded.

The locomotor activity test used an infrared detector of movement connected to a computer (LE 8811 IR motoractivity monitor, BIOSEB, Chaville, France) and was performed according to the TREAT-NMD guidelines. Test chambers were ventilated and shielded from external noise and from light. The percentage of activity, total distance covered, and maximum speed were evaluated in each animal. $\mathrm{B} 1 . \mathrm{A} / \mathrm{J}$ and $\mathrm{A} / \mathrm{J}$ mice were measured individually in-cage during 12 successive hours, from 8 PM to 8 AM.

Mice were subjected to all functional tests no more than twice to avoid a learning effect, and all of the tests were made blind, the group assignment being unknown to the observers.

\section{Biological and Histopathological Evaluation of Muscle Involvement}

\section{Serum CK and Lactate Measurement}

Mice were anesthetized with $100 \mu \mathrm{L}$ per $10 \mathrm{~g}$ of $1 \%$ pentobarbital solution diluted in $0.9 \%$ saline buffer by i.p. injection. A $500-\mu \mathrm{L}$ blood sample was taken from the right ventricle with a 1-mL syringe mounted with a 22 -gauge needle coated with heparin. The blood sample was centrifuged at $2000 \times g$ for 10 minutes at $4{ }^{\circ} \mathrm{C}$. Blood serum was frozen, stored at $-80^{\circ} \mathrm{C}$, and used within 1 month. Serum creatine kinase (CK) levels were quantified in duplicate using EnzyChrom CK Assay Kit (ECPK-100; BioAssay Systems, Hayward, CA). For each point, a $10-\mu \mathrm{L}$ sample of serum was incubated at $22^{\circ} \mathrm{C}$ in $100 \mu \mathrm{L}$ of reactive buffer following the manufacturer's protocol in a 96-well plate. The plate was read on a microplate spectrometer (SpectraMax 340PC384; Molecular Devices, St. Grégoire, France) at 340-nm wavelength after 10 and 40 minutes of incubation. CK levels were evaluated by subtracting the OD at 40 minutes from the OD at 10 minutes of each sample and then dividing by the difference between the $\mathrm{OD}$ at 40 minutes of the calibrator from the OD at 40 minutes of the blank. The final value was multiplied by 100 and given in units per liter (U/L).

Lactate levels were quantified in duplicate using lactate assay kit (K607-100; BioVision, Milpitas, CA). For each point, 1 - and $2-\mu \mathrm{L}$ samples of serum were incubated at $22^{\circ} \mathrm{C}$ in $50 \mu \mathrm{L}$ of buffer and $50 \mu \mathrm{L}$ of reaction mix following the manufacturer's protocol in a 96-well plate. The plate was read on the same microplate spectrometer at $570 \mathrm{~nm}$ wavelength after 30 minutes of incubation. Lactate level was given in nanomoles per microliter $\left(\mathrm{nmol} \cdot \mu \mathrm{L}^{-1}\right)$.

\section{Histopathological Evaluation of Muscle}

Mice were anesthetized with $100 \mu \mathrm{L}$ per $10 \mathrm{~g}$ of $1 \%$ pentobarbital solution diluted in $0.9 \%$ saline buffer by i.p. injection. Proximal muscle, ie, psoas; distal muscle, ie, extensor digitorum longus; forelimb muscles, ie, triceps brachii (triceps) and biceps brachii (biceps); and hindlimb muscles, ie, quadriceps femoris (quadriceps) and posterior thigh semimembranosus and semitendinosus (ST/SM) muscles were 
dissected. All muscles were frozen in cold isopentane maintained at $-80^{\circ} \mathrm{C}$ on dry ice. Eight-micron frozen sections were stained by histological H\&E, dehydrated via an alcohol gradient, and then mounted with Eukitt (VWR International, Strasbourg, France), according to the TREAT-NMD description guidelines. All stages of myofiber injury, ie, acute necrosis, phagocytosis, basophilic and centronucleated myofibers, were systematically counted using ImageJ software v1.37 (National Institutes of Health, Bethesda, MD) for each condition and each time.

\section{Evan's Blue Staining}

Mice were injected with $1 \%$ Evan's Blue solution in sodium buffer $(0.9 \%$ of $\mathrm{NaCl}$ in water) by an i.p. injection 16 hours before sacrifice. Muscles were then dissected, frozen, and cut according to the protocol described above. Frozen muscle sections were then mounted in VECTASHIELD Mounting Medium (Vector Laboratories, Burlingame, CA) for fluorescence imaging in the red spectrum (excitation at $620 \mathrm{~nm}$, emission at $680 \mathrm{~nm}$ ). All counts were performed using ImageJ software v1.37.

\section{Immunohistochemistry}

For myofiber typing, biceps, triceps, quadriceps, and ST/SM muscles of resting, Chron-Run, and Chron-Swim C57 and $\mathrm{B}$.A/J mice were dissected and frozen in cold isopentane $\left(-80^{\circ} \mathrm{C}\right)$. Eight-micron thin cryosections were obtained from the median part of each muscle. Sections were incubated for 1 hour in PBS Tween $0.5 \%$ at a $3 \%$ bovine serum albumin final concentration to block the nonspecific sites. Muscle sections were then probed 1 hour at room temperature with primary antibodies specific to mouse type I, II (NCLMyHCs NOVOCASTRA), IIA (gift from Helen M. Blau), and IIB (gift from S. Schiaffino) myosin heavy chain (MyHC), diluted 1:20 in PBS $0.5 \%$ Tween $3 \%$ bovine serum albumin solution for all of the antibodies. After three baths of PBS Tween $0.5 \%$, sections were incubated for 45 minutes with fluorescein isothiocyanatelabeled rabbit anti-mouse IgG DAKO1 at a 1:20 dilution in PBS $0.5 \%$ Tween $3 \%$ bovine serum albumin solution.

Specific immune complexes were visualized by epifluorescence microscopy. Images of each section were captured using camera-plot and transferred on ImageJ v1.33 software, where the total number of each type of fiber was counted by section, with a minimum of 200 fibers per type. The proportion of fiber IIX was determined as the difference between the total number of type II fibers and the number of fibers IIA+IIB.

\section{Necrosis-Regeneration Tests}

Left tibialis anterior (TA) muscle of 1-month-old Bl.A/J and C57 mice were injected with notexin solution diluted in $10 \mu \mathrm{L}$ of PBS to a final concentration of $6.3 \mu \mathrm{g} \cdot \mathrm{mL}^{-1}$, or were subjected to 10 perpendicular lesions with minutien steel pins (125- $\mu \mathrm{m}$ diameter at tip, 26002-10; F.S.T. Fine Science
Tools, Heidelberg, Germany). The right TA of each mouse was used as control. After 18 hours, 48 hours, 4 days, or 14 days, mice were anesthetized by i.p. injection with $100 \mu \mathrm{L}$ per $10 \mathrm{~g}$ of $1 \%$ pentobarbital solution diluted in $0.9 \%$ saline buffer. TA muscles were dissected, frozen in cold isopentane maintained at $-80^{\circ} \mathrm{C}$ in dry ice, and $8-\mu \mathrm{m}$ thin frozen sections were stained by histological $\mathrm{H} \& \mathrm{E}$ as described above.

\section{Electron Microscopy}

Anesthetized mice were intracardially perfused with $40 \mathrm{~mL}$ of PBS solution at $1.2 \mathrm{~mL} \cdot \mathrm{min}^{-1}$ followed by $40 \mathrm{~mL}$ of $2.5 \%$ glutaraldehyde in $0.1 \mathrm{~mol} / \mathrm{L}$ cacodylate buffer diluted in PBS at the same flow. Muscles were then dissected and incubated overnight at $4{ }^{\circ} \mathrm{C}$ with the same solution. Muscles were then divided transversally into three parts, washed three times in $0.1 \mathrm{~mol} / \mathrm{L}$ cacodylate buffer, and then postfixed with $2 \%$ osmium for 2 hours. Following three washes with cacodylate buffer, the tissue was dehydrated through a graded series of $30 \%$ to $100 \%$ ethanol, $100 \%$ propylene oxide, and then embedded in a 1:1 mixture of propylene oxide-epoxy resin (TAAB Laboratories Equipment, Aldermaston, UK) for 1 hour. After several changes of $100 \%$ resin over 24 hours, pellets were put in molds at $37^{\circ} \mathrm{C}$ overnight, followed by additional hardening at $65^{\circ} \mathrm{C}$ for two more days. Ultrathin sections of $1 \mu \mathrm{m}$ were cut, stained with $4 \%$ uranyl acetate in water for 10 minutes, followed by staining with lead citrate for 2 minutes. Sections were examined with a Tecnai 12 transmission electron microscope (FEI, Eindhoven, The Netherlands) and photographed onto electron microscope film at the electron microscopy platform of Jacques Monod Institute (University Paris 7, Paris). Membrane ruptures, fused vesicles to the plasma membrane, and papillary projection of membrane were then counted on 100 myofibers per muscle.

\section{Statistical Analysis}

All values are displayed as means and SD within each group (SYSTAT v 8.0; SPSS, Chicago, IL). A KolmogorovSmirnov normal distribution analysis was performed on all data, followed by either a Student's $t$-test for normally distributed data or a nonparametric Kruskal-Wallis test, to verify significant differences between groups.

\section{Results}

\section{The Severity of Dysferlin Myopathy Depends on Locomotor Activity}

$\mathrm{A} / \mathrm{J}$ and B6.A/J-Dysf ${ }^{\text {prmd }}(\mathrm{Bl} . \mathrm{A} / \mathrm{J})$ dysferlin-deficient murine strains share the same DYSF gene mutation but differ by their genetic background. Histopathological analysis of two hindlimb antagonist muscles, ie, quadriceps (Figure 1A) and semitendinosus/semimembranosus (ST/SM), and two forelimb antagonist muscles, ie, biceps and triceps, showed a similar pattern of involvement between both strains (Figure 1). 
A

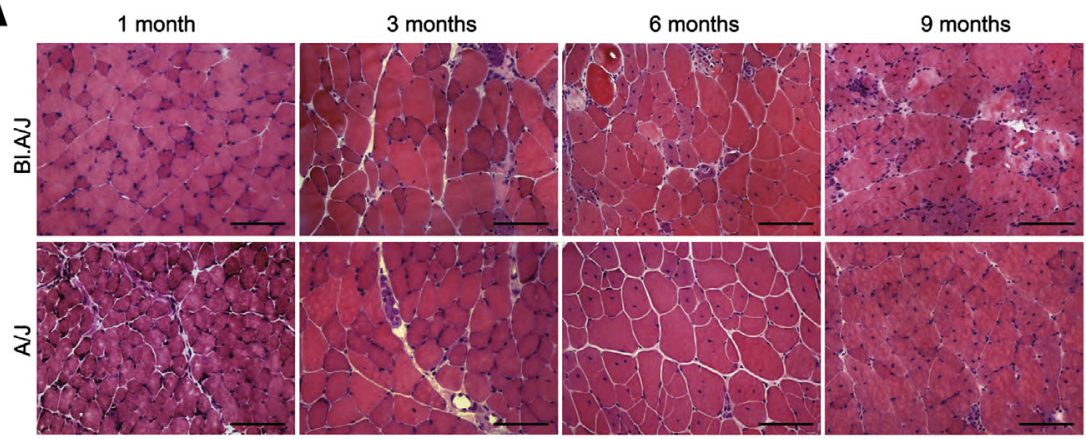

B

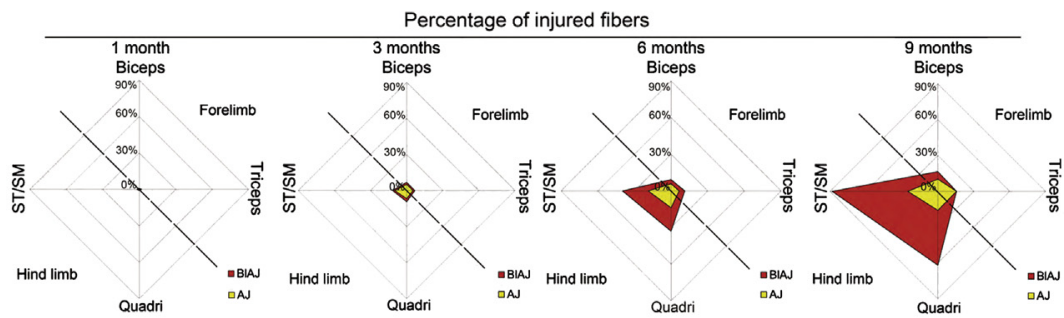

C

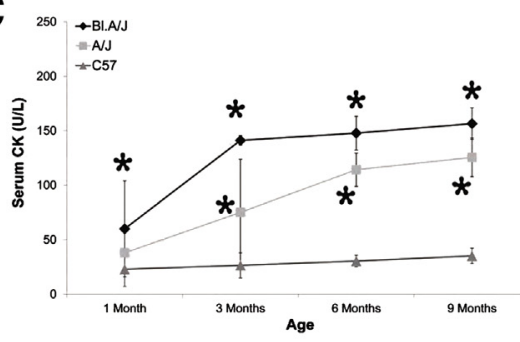

$\mathbf{E}$

D

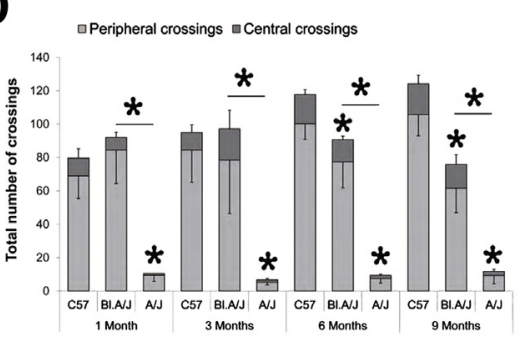

$\mathbf{F}$

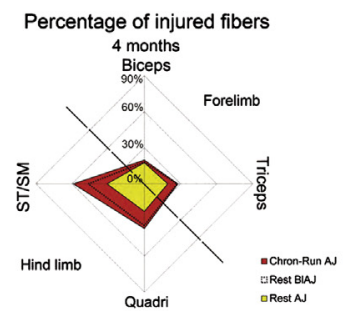

Figure 1 Comparison of two dysferlin-deficient mice models: $B$ L.A/J and A/J. A and B: Evolution of myopathy with age evidenced by histopathological examination (quadriceps, H\&E staining) in BL.A/J (A, top row) and $A / J$ (A, bottom row) mice. Scale bar $=50 \mu \mathrm{m}$. Percentage of injured fibers in two hindlimb muscles and two forelimb muscles of BL.A/ $\mathrm{J}$ (red area) and $\mathrm{A} / \mathrm{J}$ (yellow area) mice from 1 to 9 months of age $(n=6)$, showing that muscle involvement is more severe in $\mathrm{BL} . \mathrm{A} / \mathrm{J}$ compared to $\mathrm{A} / \mathrm{J}$ mice and in hindlimbs compared to forelimbs (B). Biceps, biceps brachii; quadri, quadriceps; ST/ SM, semitendinosus/semimembranosus; triceps, triceps brachii. C: Serum CK level evolution from 1 to 9 months of age $(n=6)$ showing a marked increase in dysferlin-deficient mice (BL.A/J and $\mathrm{A} / \mathrm{J}$ ) compared to normal mice (C57) from 3 months of age, and was more pronounced in $\mathrm{Bl} . \mathrm{A} / \mathrm{J}$ mice than $\mathrm{A} / \mathrm{J}$; ${ }^{*} P<0.05$. $\mathbf{D}$ and $\mathbf{E}$ : Mouse spontaneous activity evaluated by exploratory test (open-field test) from 1 to 9 months of age $(n=12)$ showing a constitutive reduction in $\mathrm{A} / \mathrm{J}$ compared to $\mathrm{C} 57$ and $\mathrm{BL} . \mathrm{A} / \mathrm{J}$ mice at any age and a decrease from 6 months in Bl.A/J compared to $\mathrm{C} 57$ mice. E: Spontaneous activity of dysferlin-deficient mice evaluated by ambulatory test (locomotor activity test) from 1 to 6 months of age $(n=6)$ confirming the specific reduction in $\mathrm{A} / \mathrm{J}$ mice; ${ }^{*} P<0.05$. F: Percentage of injured fibers in the four analyzed muscles of rest $A / J$ (yellow area) compared to rest $\mathrm{Bl} . \mathrm{A} / \mathrm{J}$ mice (dotted line) and to trained $\mathrm{A} / \mathrm{J}$ mice after 1 month of running ( $n=6$; Chron-Run A/J).

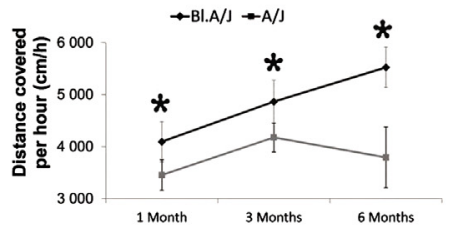

However, from 3 to 9 months, muscle injuries were more severe in B1.A/J mice (Figure 1B and Supplemental Table S1). Consistent with these findings, serum $\mathrm{CK}$ levels followed a parallel evolution with time in $\mathrm{A} / \mathrm{J}$ and $\mathrm{Bl} . \mathrm{A} / \mathrm{J}$ mice (Figure 1C), and were higher in Bl.A/J than in A/J (2-fold at 3 months, $P<0.001 ; 1.5$-fold at 6 and 9 months, $P<0.001$ ) (Figure 1C).

From these results, myopathy seems more severe in Bl.A/J than in $\mathrm{A} / \mathrm{J}$ mice. Because $\mathrm{A} / \mathrm{J}$ mice are known to have genetically determined lower locomotor activity in comparison with various other murine strains, ${ }^{28}$ we compared spontaneous locomotor activity in Bl.A/J and A/J. Using behavioral analysis of short-time spontaneous activity by open-field test and locomotor activity monitor analysis, we observed lower exploratory activity at any age in A/J mice compared to B1.A/J mice or C57 (Figure 1, D and E). Similarly, locomotor activity monitor analysis showed that the distance traveled per hour was $4092 \mathrm{~cm} \cdot \mathrm{h}^{-1}( \pm 386)$ in
Bl.A/J mice versus $3451 \mathrm{~cm} \cdot \mathrm{h}^{-1}( \pm 294)$ in A/J, 4862 $( \pm 415)$ versus $4012( \pm 278)$ and $5523( \pm 387)$ versus 3791 $( \pm 585)$ at 1,3 , and 6 months of age, respectively (Figure 1E). Lastly, when forcing $\mathrm{A} / \mathrm{J}$ mice to perform a repeated running exercise (Chron-Run protocol), the intensity of muscle injuries reached the level observed in unexercised Bl.A/J (Figure 1F and Supplemental Table S2). Taken together, these results indicate that the severity of dysferlin myopathy in mice is, at least in part, conditioned by daily life and physical activities.

\section{Exercise Is Either Beneficial or Deleterious According to the Type of Contraction}

As we have shown, activity is a determining factor of the severity of dysferlin myopathy in mice. Daily activity proceeds from the combination of different physical strains and contraction types that may be more or less stressful for muscles. To delineate the respective part of eccentric/lengthening 
contractions and concentric/shortening contractions in muscle injuries worsening, we designed two distinct longterm exercise protocols, ie, 1 month chronic running (Chron-Run) (Supplemental Video S1), in declivity and under gravity; 1 month chronic swimming (Chron-Swim) (Supplemental Video S2), without gravity strain, allowing us to subject animals to an exercise inducing either eccentric or only concentric/isometric strains. Indeed, kinematics analysis showed that the running exercise was performed downhill with a $-48 \pm 4^{\circ}$ slope (Figure $2 \mathrm{~A}$ ), allowing acute eccentric contractions on extensor muscle as triceps, quadriceps, and pelvic support as ST/SM muscles during the SP of the step, as observed by Bansal et $\mathrm{al}^{18}$ in 2003. By contrast, the swimming exercise was performed without gravity and with an inverse inclination of the body $\left(+43 \pm 8^{\circ}\right)$ (Figure 2B), preventing any eccentric contractions and injured strains. Video recording analysis showed paw movement differences on step shape during the running exercise (Figure 2C) when compared to swimming cycles (Figure 2D) on forelimb and hindlimb, associated with different shapes of muscle-load phases corresponding to the SP during running and to the PS during swimming (Figure 2, E and F). Moreover, this analysis showed kinematic differences between both exercises in terms of frequency and amplitude. The absolute step frequency was significantly higher during running compared to during the swimming exercise for forelimbs (Figure 2G), whereas it was significantly lower for hindlimbs (Figure $2 \mathrm{H}$ ). The amplitude of the muscle-loading phase was significantly lower during running SP compared to the swimming exercise PS for both limbs (Figure 2, I and J). Biochemical analysis showed increased serum creatine kinase (CK) levels after running only (Figure 2K), confirming the eccentric muscle load, and increased serum lactate levels after swimming only (Figure 2L). Finally, as expected, both types of exercise provide contrasting effects in all movement and physiological parameters, with a muscle-injuring one in the running condition and a muscle-preserving one in the swimming condition.

To ensure easy detection of dystrophic process changes, these exercise protocols were carried out on 3-month-old animals, an age when myopathy is at its early stage in $\mathrm{Bl} . \mathrm{A} / \mathrm{J}$ mice $(<1 \%$ of necrotic fibers), and were calibrated to remain within physiological limits and to not induce myofiber necrosis in normal animals (Supplemental Table S3), in contrast to other eccentric protocols. ${ }^{17}$ After 1 month of repeated running or swimming exercises, we observed a transition toward a slower phenotype of the four studied muscles in Bl.A/J and C57 mice, ensured by the transition from fast IIb to IIx/d myofibers and from IIx/d to intermediate IIa myofibers (Figure 3, A and B), but not from IIa to slow I myofibers (Figure 3B). These results indicate that running and swimming exercises induce a significant overload on the examined muscles. Most importantly, this muscle overload appears more pronounced after the swimming protocol and predominantly affects forelimb muscles.

However, only Chron-Run Bl.A/J mice displayed worsening of myonecrotic process $(P<0.01)$ (Figure 4 , A and B,
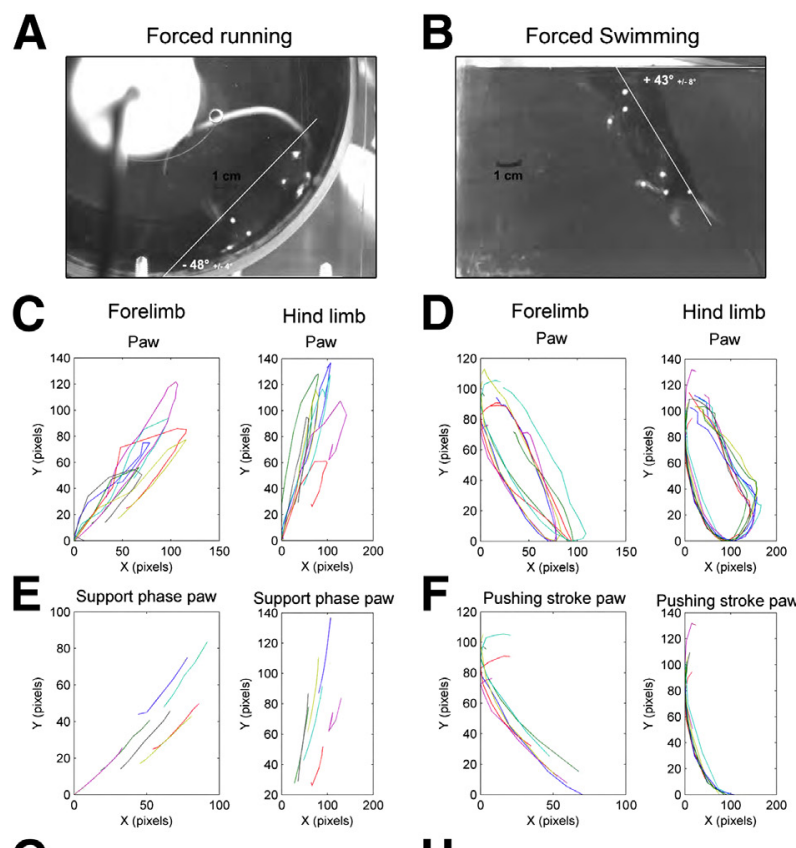

G

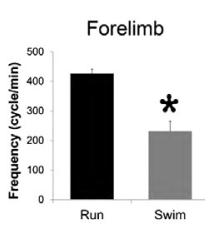

H

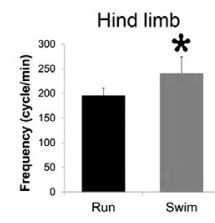

I

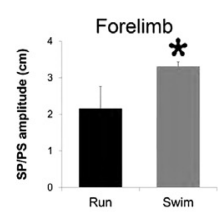

$\mathbf{J}$
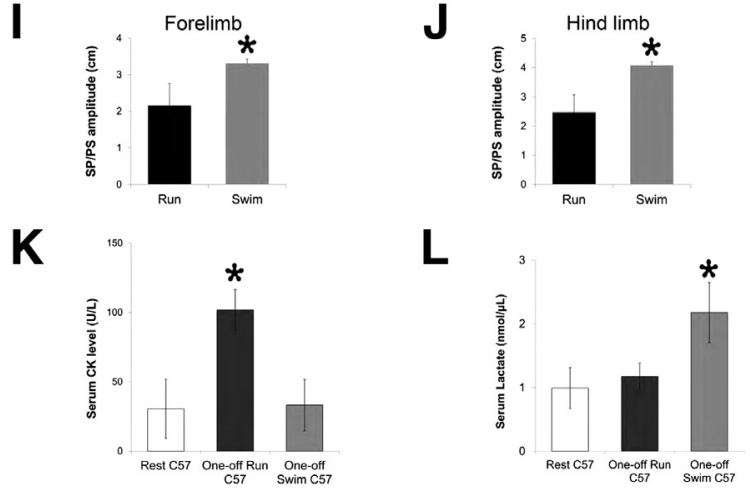

Figure 2 Characterization of exercise protocols. A and B: Images from video recordings showing $\mathrm{C} 57$ mice in the motor-powered wheel during the forced running exercise $(\mathbf{A})$ or in the adjustable-flow pool during the forced swimming exercise (B). Mice limbs are tagged with white markers at each joint, and lines indicate the anteroposterior axes of mice and their inclinations with respect to the horizontal. C and D: Tracking of the paw movement during running (C) and swimming (D), in forelimbs (left panels) and hindlimbs (right panels). E and F: Tracking of the SP during the running step cycle (E) and the pushing stroke (PS) during swimming step cycle (F), in forelimbs (left panels) and hindlimbs (right panels). $\mathbf{G}$ and $\mathbf{H}$ : Absolute frequency of movement in forelimb (G) and hindlimb $(\mathbf{H})$. I and $\mathbf{J}$ : Amplitude of SP (running) or PS (swimming) in forelimb (I) and hindlimb (J), named SP/PS amplitude. K: Serum CK levels in Rest, One-off Run, and One-off Swim C57 control mice. L: Serum lactate levels in Rest, One-off Run, and One-off Swim $C 57$ control mice $(n=6)$; ${ }^{\star} P<0.05$.

and Supplemental Table S4) in a muscle-dependent manner. Indeed, an increase in the number of injured fibers was observed in the eccentrically involved triceps, quadriceps, and ST/SM muscles, but not in concentrically involved biceps muscle $(+3 \%$ in triceps and quadriceps; $+9 \%$ in 

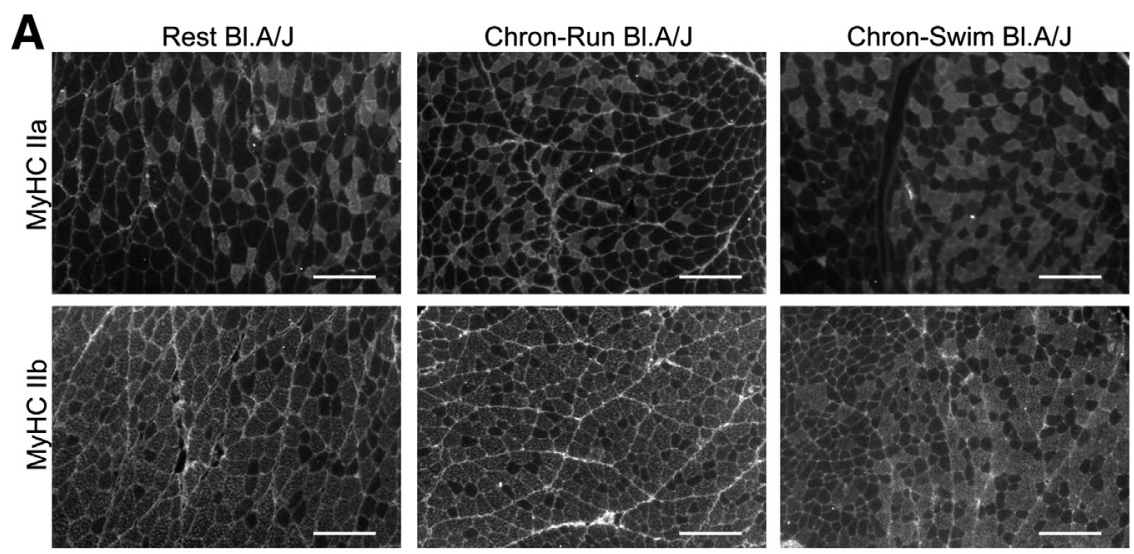

B
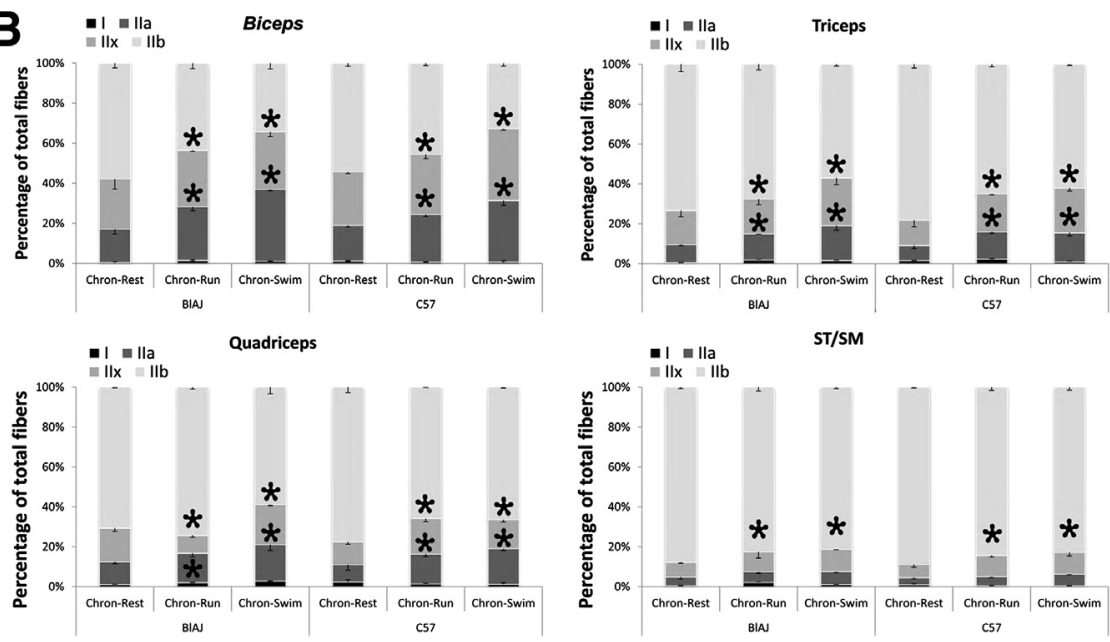

Figure 3 Changes of muscle fiber typology induced by two types of exercise in normal and dysferlin deficient mice. A: Immunofluorescence staining of myosin heavy chain type (MyHC) IIa (top row) and IIb (bottom row) in quadriceps muscles from 4-month-old resting Bl.A/J (Rest Bl.A/J) (left panels) and trained BL.A/J mice after 1 month of running (Chron-Run BL.A/J; middle panels) or swimming (Chron-Swim Bl.A/J) (right panels). Scale bar $=100 \mu \mathrm{m}$. B: Percentage of type I, IIa, IIx, and IIb fibers assessed by MyHC isoforms immunostaining in two hindlimb muscles and two forelimb muscles of Rest, Chron-Run, and Chron-Swim Bl.A/J and $\mathrm{C} 57$ mice showing comparable physical overload in $\mathrm{BL} . \mathrm{A} / \mathrm{J}$ compared to $\mathrm{C} 57$ mice after both exercises, which induced a switch of muscle fiber typology to a slower phenotype, with more pronounced effect in forelimbs compared to hindlimb muscles and for swimming compared to running exercise $(n=6)$; ${ }^{*} P<0.05$. Biceps, biceps brachii; quadri, quadriceps; ST/SM, semitendinosus/semimembranosus; triceps, triceps brachii.
ST/SM; $P<0.01$ ) (Figure 4, A and B, and Supplemental Table S4). This worsening of muscle injuries paralleled strength decrease (forelimbs: $-38 \mathrm{~g}$ of grip force, $P<0.001$; hindlimbs: $-35 \mathrm{~g}, P<0.01$ ) (Figure 4D), and serum CK level increase $(+26 \% ; P<0.05)$ (Figure $4 \mathrm{C})$. By contrast, Chron-Swim Bl.A/J mice displayed a muscle strength improvement compared to Rest and Chron-Run Bl.A/J mice (forelimbs: $+16 \mathrm{~g}$ of grip force, $P<0.01$; hindlimbs: $+34 \mathrm{~g}$ of grip force, $P<0.01$; Figure 4D), and a serum CK level decrease compared to Chron-Run Bl.A/J mice $(-38 \% ; P<$ 0.05 ) (Figure 4C). These effects were associated with increased spontaneous activity and behavioral changes, as assessed by a total crossing increase and shift from central to peripheral crossing $(P<0.01)$ (Figure $4 \mathrm{E})$.

Taken together, the worsening of dystrophic process concerns eccentrically involved muscles only and is not linked to muscle overload, as assessed by fiber type transitions.

\section{Eccentric Exercise-Induced Myofibers Necrosis Is Delayed in an Age-Dependent Manner in Bl.A/J Mice}

To investigate the mechanism of exercise-induced worsening of dystrophic process in Bl.A/J mice, we submitted presymptomatic 1-month-old Bl.A/J mice and affected 3-monthold $\mathrm{Bl} . \mathrm{A} / \mathrm{J}$ mice to a unique bout of the running exercise
(One-off Run) in the rodent wheel to track the necrosis regeneration process. To allow this tracking, we used histological assessment of necrotic fibers and Evan's Blue vital staining of membrane permeability from 1 to 20 days postexercise. One-off Run C57 mice did not display any increase in necrotic process for any observed muscles (Supplemental Table S3) even if an increase of serum CK level was observed 1 day after exercise (Supplemental Figure S1). This indicates that a unique running exercise induced sarcolemma lesions without necrotic process. However, in Bl.A/J mice, this specific exercise induced myofiber necrosis on eccentrically involved muscles, ie, triceps, quadriceps, and ST/SM (Figure 5). At 1 month of age, all of the analyzed muscles except the biceps displayed a delayed necrotic process only from the 10th day after exercise in Bl.A/J mice (Figure 5, B, C, $\mathrm{D}$, and $\mathrm{E}$ ), whereas an increase in serum $\mathrm{CK}$ level was observed from the first day (Supplemental Figure S2). At 10 days after exercise, the percentage of necrotic fibers increased by 7-fold in triceps (Figure 5C), 3.5-fold in quadriceps (Figure 5D), and 5.5-fold in ST/SM (Figure 5E) when compared to rest $\mathrm{B} 1 . \mathrm{A} / \mathrm{J}$ muscles $(P<0.05)$. This exercise effect was still observed at 20 days after exercise but to a lower level $(P<0.05)$. The significant increase in the number of necrotic myofibers, similarly evidenced by both HE and Evan's Blue staining, cannot be ascribed to a regeneration 

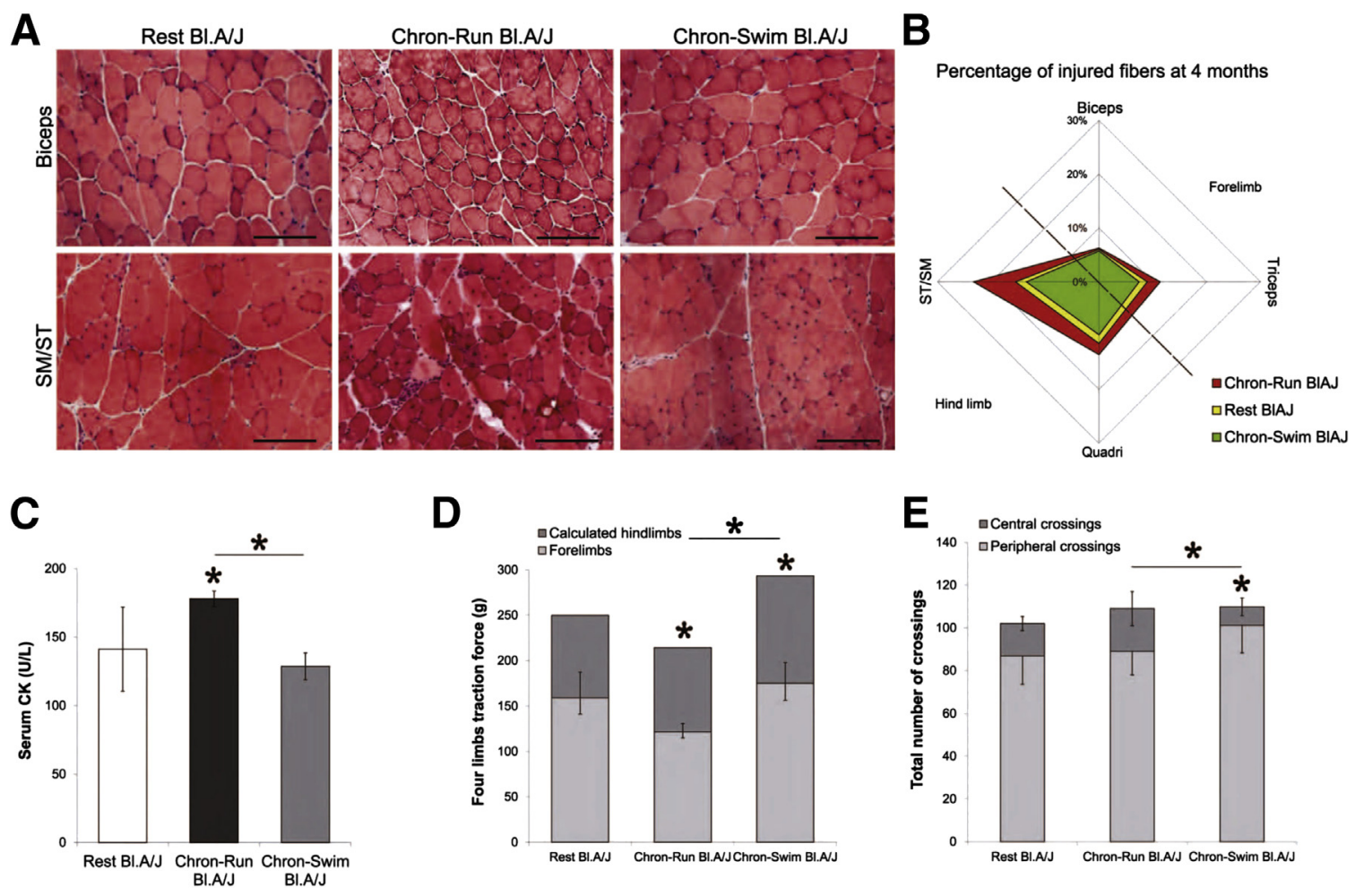

Figure 4 Exercise pattern modulates muscle injuries in dysferlin-deficient Bl.A/J mice. A and B: Effects of two types of exercise on the evolution of muscle dystrophic process evidenced by histopathological examination (quadriceps, HE staining) in trained BL.A/J mice after 1 month of running (Chron-Run Bl.A/J) (A, middle panels) and swimming (Chron-Swim Bl.A/J) (A, right panels) compared to resting Bl.A/J mice (Rest Bl.A/J) (A, left panels) at 4 months of age. Scale $\mathrm{bar}=50 \mu \mathrm{m}$. Percentage of injured fibers in two hindlimb muscles and two forelimb muscles of Rest BL.A/J (yellow area), compared to Chron-Run BL.A/J (red area) and Chron-Swim Bl.A/J mice (green area) at 4 months of age $(n=6)$, showing that running increased the dystrophic process only in eccentrically involved muscles (ST/SM, Quadri, and Triceps) and that swimming was devoid of any deleterious effect (B). Biceps, biceps brachii; quadri, quadriceps; ST/SM, semitendinosus/ semimembranosus; triceps, triceps brachii. C: Serum CK level determination in BL.A/J mice showing increase after chronic running and decrease after chronic swimming compared to resting at 4 months of age $(n=6)$. D: Forelimbs and calculated hindlimb traction strength measurement (grip force test) in Bl.A/J mice showing decrease after chronic running and increase after chronic swimming $(n=6)$ at 4 months of age. E: Mouse spontaneous activity evaluated by exploratory test (open-field test) in BL.A/J showing an increase in Chron-Swim Bl.A/J compared to Chron-Run and Rest Bl.A/J mice $(n=6)$ at 4 months of age. ${ }^{*} P<0.05$.

default in Bl.A/J mice, because no delay in necrosis and regeneration of myofibers was observed after needle wounding or notexin injury at the same age (Supplemental Figure S3). At 3 months of age, necrotic process occurred earlier in the three eccentrically involved muscles, but not in the biceps muscle. The triceps muscle displayed a necrotic process increase from 1 to 20 days, with two peaks of necrosis, one at 1 day after exercise and the other 5 days after exercise (2.5-fold at 1 day; 1.5 -fold at 3 days; 2.5 -fold at 5 and 10 days; 2-fold at 20 days after exercise) (Figure 5, C, D, and E). This pattern was almost similar in the others muscles, with the two peaks of necrosis at 1 and 5 days after exercise, but with a mean increase of 1.5 -fold for each muscle $(P<0.05)$. These results indicate that eccentric strain induces myofiber necrosis after a delay, which decreases with age, witnessing dysferlindeficient muscle susceptibility to injuring exercise with time.

\section{Delayed Necrosis of Myofibers in Bl.A/J Mice Is Due to the Accumulation of Nonlethal Membrane Damage}

To confirm the role of membrane damage accumulation (Figure 6, A, B, and C) at the origin of myofiber necrosis in dysferlinopathy and to explain the delayed necrosis of myofibers, we used electron microscopy to quantify sarcolemma disruptions (Figure 6A) induced by different types of exercise, before the expected onset of myofiber necrosis. The analysis was performed 5 days after one-off exercise in 1-month-old Bl.A/J and C57 mice, at a time when necrotic fibers are not yet observed after the running exercise and before symptoms occurrence. We evaluated muscles differently affected by exercise, ie, quadriceps muscle (injured) and biceps muscle (noninjured), in all conditions (running, swimming, and rest).

In B1.A/J mice, the baseline number of membrane ruptures was 5- and 9-fold higher in biceps and quadriceps muscles, respectively, when compared to C57 mice $(P<0.05)$, whereas no fiber necrosis could be observed (Figure 6D). When subjected to a One-off Run, the quadriceps muscle of $\mathrm{B}$.A/J mice displayed a 2.5 -fold increase in the number of membrane ruptures when compared to the One-off Swim and Rest $(P<0.05)$. By contrast, no significant difference was observed in biceps muscle, even if its baseline number of membrane ruptures was higher compared to C57, with around five ruptures per section and per fiber. Finally, in C57 

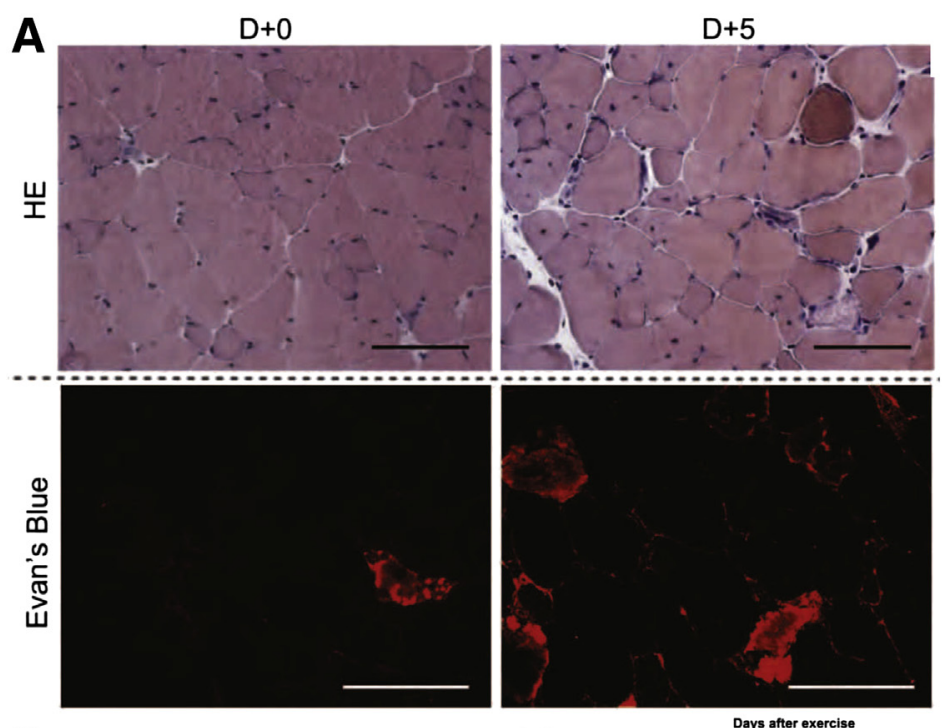

B
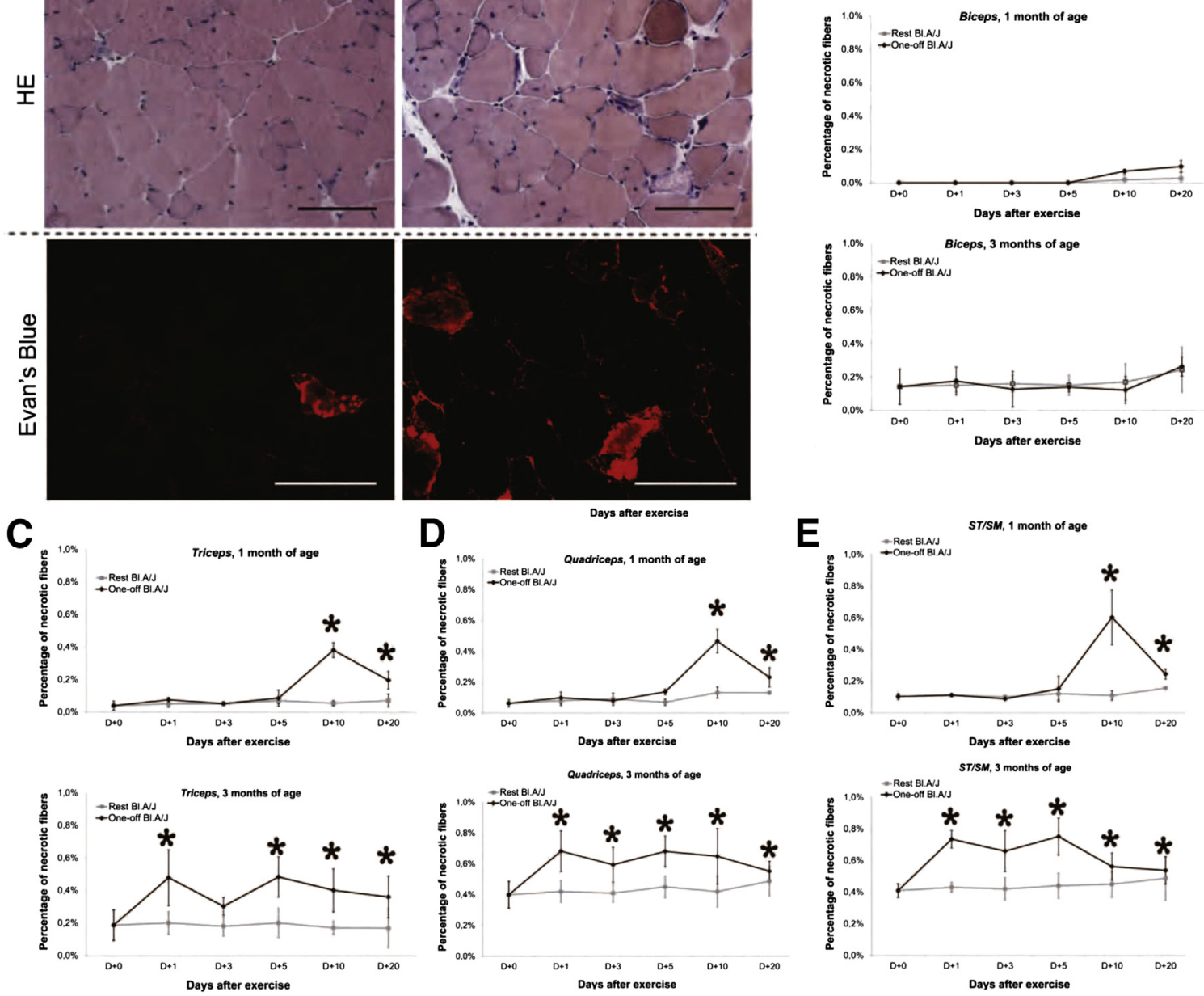

Figure 5 Effects of one-off running exercise on myofiber necrosis in dysferlin-deficient BL.A/J mice. A-E: Evaluation of acute myofiber necrosis assessed by HE staining (A, top row) (Scale bar $=50 \mu \mathrm{m}$ ) and Evan's Blue uptake (A, bottom row) (Scale bar $=25 \mu \mathrm{m})$ in quadriceps muscles from 3-month-old unexercised Bl.A/J mice $(D+0)(A$, left panels) and 5 days after one-off running $B l . A / J(D+5)(A$, right panels). Percentage of acute necrotic fibers evolution at $0(D+0), 1(D+1), 3(D+3), 5(D+5), 10(D+10)$, and $20(D+20)$ days in biceps brachii (B), triceps brachii (C), quadriceps (D), and semitendinosus/semimembranosus (E) of 1-month-old (top graphs) and 3-month-old (bottom graphs) Bl.A/J mice $(n=5)$ subjected to one-off running, showing delayed increase in eccentrically involved muscles only (Triceps, Quadriceps, and ST/SM), this delay being inversely proportional to the mice age. ${ }^{*} P<0.05$. Biceps, biceps brachii; quadri, quadriceps; ST/SM, semitendinosus/semimembranosus; triceps, triceps brachii.

mice, one-off exercise did not show any significant effect in any of the muscles or type of exercise used, with a mean of one rupture per section and per fiber (Figure 6D).

Taken together, our results showed that in dysferlin deficiency, the pre-symptomatic stage of myopathy is characterized by an accumulation of plasma membrane ruptures in non-necrotic fibers, a feature modulated by the type of physical strain. Eccentric strain markedly increases the number of accumulated membrane lesions whereas concentric exercise does not.

\section{Discussion}

Muscle dystrophies form a heterogeneous group of inherited diseases, whose common feature is the progressive muscle weakness paralleling muscle degeneration. In Duchenne muscular dystrophy, muscle degeneration relates to the increased myofiber vulnerability to physical stress leading to extensive myonecrosis and the growing difficulties for patients to sustain physical efforts. Conversely, dysferlindeficient myofibers display a normal resistance toward physical strains. Dysferlinopathies strikingly differ from other dystrophies by a set of unexplained clinical peculiarities, including among others: i) a high proportion of patients practicing various sports or being very active prior the onset of symptoms; ii) the nonlinear course of illness; iii) the marked phenotypic heterogeneousness. In the present work, we documented the dual effect of exercise in dysferlinopathy. On the one hand, eccentric strain likely determines both the pattern and course of the dystrophic process, depending on the capacity of myofibers to accept nonlethal sarcolemma rupture accumulation up to a necrosis threshold. On the other hand, concentric/isometric exercise unambiguously improved the myopathy, likely because the lack of additional 

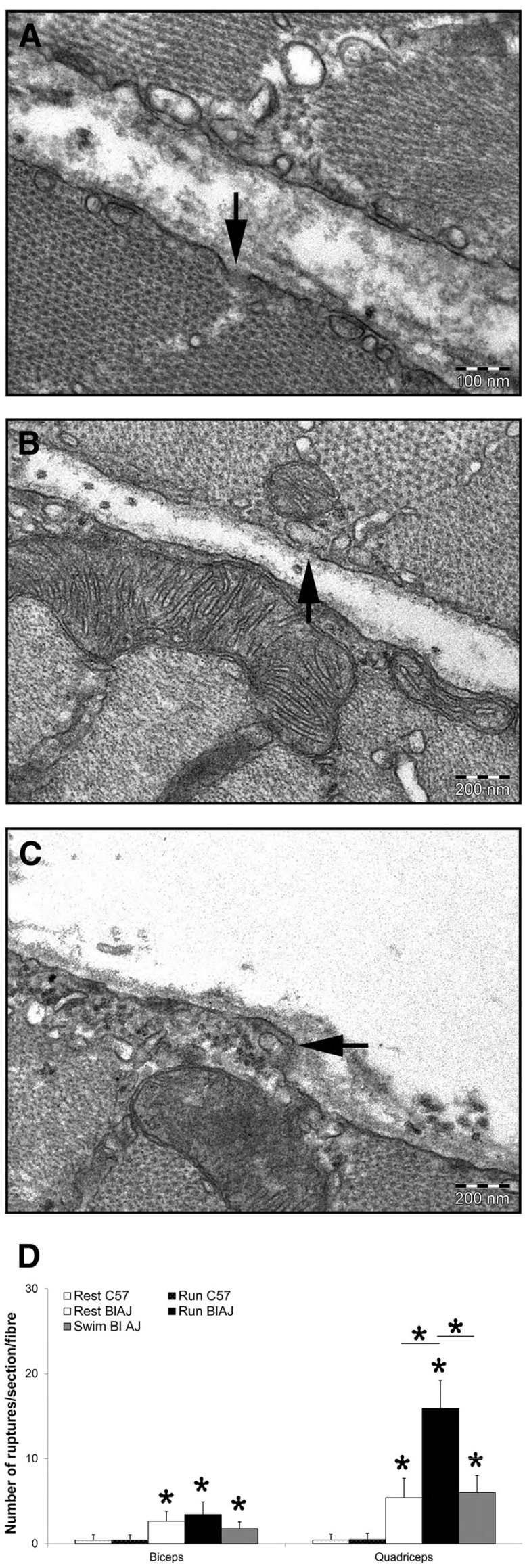

sarcolemma ruptures associated with this regimen allowed muscle to benefit from a training effect.

By comparing $\mathrm{A} / \mathrm{J}$ and $\mathrm{Bl} . \mathrm{A} / \mathrm{J}$ mice, two strains with the same DYSF mutation, but different genetic background, we observed a similar pattern of muscle involvement and serum $\mathrm{CK}$ level, but a slower progression in $\mathrm{A} / \mathrm{J}$ leading to a milder phenotype from 3 to 9 months. These data pointed out the role of epigenetic and environmental factors in the expression of disease. Interestingly, A/J mice differ from C57 mice by two major genetic traits. First, A/J mice display a deficiency in the C5 factor of complement. ${ }^{29}$ Complement activation leading to the formation of membrane attack complex (C5b-9, MAC) at the surface of myofibers is a feature of dysferlinopathy, which could contribute to muscle injuries. ${ }^{30}$ However, the specific C5 ablation is devoid of any positive effect, ${ }^{31}$ and therefore the differences observed between $\mathrm{A} / \mathrm{J}$ and Bl.A/J mice cannot be ascribed to C5 deficiency only. Second, A/J mice display reduced locomotor activity, a trait associated with less developed motor axons. ${ }^{32}$ The transfer of $\mathrm{A} / \mathrm{J}$ dysferlin mutation operated onto C57/B16 strain (B1.A/J) allowed restoration of a normal spontaneous activity with parallel increase of muscle injuries. Moreover, subjecting A/J and Bl.A/J mice to a daily running activity consistently induced a worsening of muscle injuries. Such a vulnerability to running emphasized the impact of activity on the severity of the dystrophic process. In addition, SJL mice are another dysferlin-deficient model mice well known for their aggressiveness. ${ }^{33}$ These overactive mice were described as the most severe model of dysferlinopathy, despite $15 \%$ of dysferlin residual expression. ${ }^{34}$ Therefore, the comparison of different dysferlin-deficient mice supports a role for daily life activity, a mixture of eccentric, isometric, and concentric muscle contraction regimen, ${ }^{35,36}$ in determining the intensity of muscle involvement. Taken together, our findings may be a key for understanding the clinical heterogeneity of dysferlinopathy in humans, in terms of pattern and severity, even within the same family.

During physical activities, muscle groups are differently involved. To determine the respective role for each component of physical activity on the dystrophic process, we subjected $\mathrm{Bl}$.A/J mice to a long-term running exercise in a forced-running wheel or a long-term swimming exercise. We demonstrated that both antagonist and proximal limb muscles were overloaded in all exercise conditions, as assessed by a muscle phenotype transition from fast to intermediate. ${ }^{26}$ Indeed, the rate of myonecrosis was very low and unrelated to the degree of fiber type conversion. So, the changes in fiber type profile could not be

\footnotetext{
Figure 6 Effects of one-off exercises on membrane rupture accumulation in dysferlin-deficient BL.A/J mice. A-C: Electron microscopy examination of membrane abnormalities (designated by an arrow) in quadriceps muscle from 1-month-old BL.A/J mice 5 days after being subjected to one-off running with membrane rupture (A), subsarcolemmal vesicles fused to membrane (B), and papillary membrane projection (C). D: Quantification of membrane ruptures in biceps and quadriceps muscles from normal C57 mice at rest (Rest C57) and after one-off running (Run C57), and from dysferlin-deficient BL.A/J mice at rest (Rest Bl.A/J), after one-off running (Run BL.A/J) and swimming (Swim $B L . A / J)$ at 1 month of age, showing increase in eccentrically involved quadriceps of Run Bl.A/J mice only $(n=3) ;{ }^{*} P<0.05$.
} 
explained by the extent of muscle injury, but reflected the muscle adaption to physical strain. Interestingly, the muscles' phenotype transition was more pronounced in forelimbs compared to hindlimbs, suggesting prominent overload in these muscles compared to their daily standard activity. Phenotype transition was also most important in muscles subjected to swimming, but this exercise regimen (concentric/isometric exercise) was completely devoid of any deleterious effects, and was even associated with an increase in motor performances. By contrast, running, with eccentric strains on, for example, triceps, $\mathrm{SM} / \mathrm{ST}$, and quadriceps muscles, induced a worsening of dystrophic process. Thus, the severity of the muscular dystrophic process in dysferlin deficiency seems to be directly correlated to the type of physical strain and not to muscle overload.

The phenotype of murine dysferlin myopathy appears stereotyped compared to human disease, with only an LGMDtype muscle impairment distribution, whatever the DYSF gene mutation and genetic background (http://www.jain-foundation. org/our-dysferlin-research-institute/research-tools/mousemodels-dysferlin-deficiency, last accessed February 2, 2012). This could be explained by a comparable environmental stress on all type of mice due to standard housing conditions.

Running induced a marked CK level increase, even in control mice, reflecting plasma membrane damage immediately after efforts. ${ }^{37,38}$ In Bl.A/J mice, CK elevation occurs immediately after efforts, whereas myonecrosis was delayed by 1 and 5 postexercise days at 3 months of age. This was consistent with previous lengthening contraction experiments carried out on 3- and 4-month-old A/J mice, showing at least 3 days of myofiber survival after injury, a feature ascribed to the activation of intrinsic survival mechanisms in injured myofibers. ${ }^{39}$ However, at 1 month of age, the first necrosis was only observed 10 days after the running exercise, suggesting a link between age and myofiber susceptibility to exercise in individuals with dysferlin deficiency.

In control mice, exercise-induced myonecrosis is always observed immediately after efforts, whatever the age. In Bl.A/J mice, sarcolemma ruptures were detected by electronic microscopy long before myonecrosis, when animals displayed normal muscle strength and locomotor abilities. Accordingly, at 1 month of age, resting Bl.A/J mice did not display myonecrosis during the 20 days of experiments, despite likely ongoing membrane rupture accumulation. However, a unique bout of running was sufficient to induce first necrosis during this period. This suggest that myofibers are able to survive with an elevated number of membrane rupture up to a defined threshold after which myonecrosis occurs. Consistently, although running was able to accelerate this process, swimming exercise did not modify the time course of the accumulation of membrane ruptures nor induce myofiber necrosis. Moreover, the concentric exercise could induce muscular adaptations to the elevation of physical strain, including the modification of contractile protein expression, metabolic enzymes expression, and structural changes, which increase muscle strength and, subsequently, protect the muscle against further damage-induced daily life activity.
In light of our experimental results, the clinical heterogeneity of dysferlinopathies could be analyzed through the type and intensity of exercise to which patients were subjected. The high proportion of previously very active and sporty individuals among patients with dysferlinopathies reinforce our physiopathological model. ${ }^{16}$ It is likely that during the pre-symptomatic phase, membrane ruptures accumulate without any effect on motor capabilities. The eccentric strain induced by their activity likely modifies the time course of membrane accumulation, shaping distribution and evolution of dystrophic process. Interestingly, all types of reported activities are known to induce a high proportion of eccentric contractions, eg, horseriding, dancing, running, and playing football, and none of the patients were known to regularly do exclusively concentric/isometric exercise, such as swimming or cycling. On the basis of the present study, it could be interesting to dissect the past physical activities of patients in all of their features, strain component, and intensity, according to the different clinical forms of dysferlinopathies to confirm the exercise role on disease progression and phenotype (MM versus LGMD2B)

At present, therapeutic perspectives in dysferlinopathies mainly include the restoration of dysferlin expression by gene transfer or exon skipping, and pharmacological approaches based on the modulation of inflammatory processes, as complement inhibition. ${ }^{13,40}$ However, these promising approaches are far from being routinely applicable to patients. By contrast, our findings provide an innovative therapeutic way based on a physiotherapy approach, using concentric/isometric exercise training and avoiding any eccentric strain. This immediately available therapy will improve patient muscle strength without inducing membrane damage, providing the trained muscles with a better resistance to further contractions.

\section{Acknowledgment}

We thank Prof. Frederic Charbonnier (UMR 8194, Université Paris Descartes, Paris, France), who allowed us to use the patented experimental swimming pool for mice.

\section{Supplemental Data}

Supplemental material for this article can be found at http://dx.doi.org/10.1016/j.ajpath.2013.02.045.

\section{References}

1. Bashir R, Britton S, Strachan T, Keers S, Vafiadaki E, Lako M, Richard I, Marchand S, Bourg N, Argov Z, Sadeh M, Mahjneh I, Marconi G, Passos-Bueno MR, Moreira Ede S, Zatz M, Beckmann JS, Bushby K: A gene related to Caenorhabditis elegans spermatogenesis factor fer- 1 is mutated in limb-girdle muscular dystrophy type $2 \mathrm{~B}$. Nat Genet 1998, 20:37-42

2. Ho M, Gallardo E, McKenna-Yasek D, De Luna N, Illa I, Brown RH Jr.: A novel, blood-based diagnostic assay for limb girdle muscular dystrophy 2B and Miyoshi myopathy. Ann Neurol 2002, 51: $129-133$ 
3. Jethwaney D, Islam MR, Leidal KG, de Bernabe DB, Campbell KP, Nauseef WM, Gibson BW: Proteomic analysis of plasma membrane and secretory vesicles from human neutrophils. Proteome Sci 2007, $5: 12$

4. De Luna N, Freixas A, Gallano P, Caselles L, Rojas-Garcia R, Paradas C, Nogales G, Dominguez-Perles R, Gonzalez-Quereda L, Vilchez JJ, Marquez C, Bautista J, Guerrero A, Salazar JA, Pou A, Illa I, Gallardo E: Dysferlin expression in monocytes: a source of mRNA for mutation analysis. Neuromuscul Disord 2007, 17:69-76

5. Bushby KM: The limb-girdle muscular dystrophies: multiple genes, multiple mechanisms. Hum Mol Genet 1999, 8:1875-1882

6. Liu J, Aoki M, Illa I, Wu C, Fardeau M, Angelini C, Serrano C, Urtizberea JA, Hentati F, Hamida MB, Bohlega S, Culper EJ, Amato AA, Bossie K, Oeltjen J, Bejaoui K, McKenna-Yasek D, Hosler BA, Schurr E, Arahata K, de Jong PJ, Brown RH Jr.: Dysferlin, a novel skeletal muscle gene, is mutated in Miyoshi myopathy and limb girdle muscular dystrophy. Nat Genet 1998, 20:31-36

7. Paradas C, Gonzalez-Quereda L, De Luna N, Gallardo E, GarciaConsuegra I, Gomez H, Cabello A, Illa I, Gallano P: A new phenotype of dysferlinopathy with congenital onset. Neuromuscul Disord 2009, 19:21-25

8. Klinge L, Dean AF, Kress W, Dixon P, Charlton R, Muller JS, Anderson LV, Straub V, Barresi R, Lochmuller H, Bushby K: Late onset in dysferlinopathy widens the clinical spectrum. Neuromuscul Disord 2008, 18:288-290

9. Nguyen K, Bassez G, Bernard R, Krahn M, Labelle V, FigarellaBranger D, Pouget J, Hammouda el H, Beroud C, Urtizberea A, Eymard B, Leturcq F, Levy N: Dysferlin mutations in LGMD2B. Miyoshi myopathy, and atypical dysferlinopathies. Hum Mutat 2005, 26:165

10. Seror P, Krahn M, Laforet P, Leturcq F, Maisonobe T: Complete fatty degeneration of lumbar erector spinae muscles caused by a primary dysferlinopathy. Muscle Nerve 2008, 37:410-414

11. Illa I, Serrano-Munuera C, Gallardo E, Lasa A, Rojas-Garcia R, Palmer J, Gallano P, Baiget M, Matsuda C, Brown RH: Distal anterior compartment myopathy: a dysferlin mutation causing a new muscular dystrophy phenotype. Ann Neurol 2001, 49:130-134

12. Nguyen K, Bassez G, Krahn M, Bernard R, Laforet P, Labelle V, Urtizberea JA, Figarella-Branger D, Romero N, Attarian S, Leturcq F, Pouget J, Levy N, Eymard B: Phenotypic study in 40 patients with dysferlin gene mutations: high frequency of atypical phenotypes. Arch Neurol 2007, 64:1176-1182

13. Han R: Muscle membrane repair and inflammatory attack in dysferlinopathy. Skelet Muscle 2011, 1:10

14. Paradas C, Llauger J, Diaz-Manera J, Rojas-Garcia R, De Luna N, Iturriaga C, Marquez C, Uson M, Hankiewicz K, Gallardo E, Illa I: Redefining dysferlinopathy phenotypes based on clinical findings and muscle imaging studies. Neurology 2010, 75:316-323

15. Orell SR: Radial scar/complex sclerosing lesion-a problem in the diagnostic work-up of screen-detected breast lesions. Cytopathology 1999, 10:250-258

16. Klinge L, Aboumousa A, Eagle M, Hudson J, Sarkozy A, Vita G, Charlton R, Roberts M, Straub V, Barresi R, Lochmuller H, Bushby K: New aspects on patients affected by dysferlin deficient muscular dystrophy. J Neurol Neurosurg Psychiatry 2010, 81:946-953

17. Bansal D, Campbell KP: Dysferlin and the plasma membrane repair in muscular dystrophy. Trends Cell Biol 2004, 14:206-213

18. Bansal D, Miyake K, Vogel SS, Groh S, Chen CC, Williamson R, McNeil PL, Campbell KP: Defective membrane repair in dysferlindeficient muscular dystrophy. Nature 2003, 423:168-172

19. Selcen D, Stilling G, Engel AG: The earliest pathologic alterations in dysferlinopathy. Neurology 2001, 56:1472-1481

20. McNeil PL, Steinhardt RA: Loss, restoration, and maintenance of plasma membrane integrity. J Cell Biol 1997, 137:1-4

21. McNeil PL, Vogel SS, Miyake K, Terasaki M: Patching plasma membrane disruptions with cytoplasmic membrane. J Cell Sci 2000, 113(Pt 11):1891-1902
22. McNeil PL, Terasaki M: Coping with the inevitable: how cells repair a torn surface membrane. Nat Cell Biol 2001, 3:E124-E129

23. De Luna N, Gallardo E, Sonnet C, Chazaud B, Dominguez-Perles R, Suarez-Calvet X, Gherardi RK, Illa I: Role of thrombospondin 1 in macrophage inflammation in dysferlin myopathy. J Neuropathol Exp Neurol 2010, 69:643-653

24. Faulkner JA, Brooks SV, Opiteck JA: Injury to skeletal muscle fibers during contractions: conditions of occurrence and prevention. Phys Ther 1993, 73:911-921

25. Lostal W, Bartoli M, Bourg N, Roudaut C, Bentaib A, Miyake K, Guerchet N, Fougerousse F, McNeil P, Richard I: Efficient recovery of dysferlin deficiency by dual adeno-associated vector-mediated gene transfer. Hum Mol Genet 2010, 19:1897-1907

26. Grondard C, Biondi O, Pariset C, Lopes P, Deforges S, Lecolle S, Gaspera BD, Gallien CL, Chanoine C, Charbonnier F: Exerciseinduced modulation of calcineurin activity parallels the time course of myofibre transitions. J Cell Physiol 2008, 214:126-135

27. Gruner JA, Altman J: Swimming in the rat: analysis of locomotor performance in comparison to stepping. Exp Brain Res 1980, 40: 374-382

28. Kas MJ, de Mooij-van Malsen AJ, Olivier B, Spruijt BM, van Ree JM: Differential genetic regulation of motor activity and anxiety-related behaviors in mice using an automated home cage task. Behav Neurosci 2008, 122:769-776

29. Tuite A, Elias M, Picard S, Mullick A, Gros P: Genetic control of susceptibility to Candida albicans in susceptible A/J and resistant C57BL/6J mice. Genes Immun 2005, 6:672-682

30. Wenzel K, Zabojszcza J, Carl M, Taubert S, Lass A, Harris CL, Ho M, Schulz H, Hummel O, Hubner N, Osterziel KJ, Spuler S: Increased susceptibility to complement attack due to down-regulation of decayaccelerating factor/CD55 in dysferlin-deficient muscular dystrophy. J Immunol 2005, 175:6219-6225

31. Han R, Frett EM, Levy JR, Rader EP, Lueck JD, Bansal D, Moore SA, Ng R, Beltran-Valero de Bernabe D, Faulkner JA, Campbell KP: Genetic ablation of complement $\mathrm{C} 3$ attenuates muscle pathology in dysferlin-deficient mice. J Clin Invest 2010, 120:4366-4374

32. de Mooij-van Malsen JG, van Lith HA, Oppelaar H, Olivier B, Kas MJ: Evidence for epigenetic interactions for loci on mouse chromosome 1 regulating open field activity. Behav Genet 2009, 39:176-182

33. Page DL, Glenner GG: Social interaction and wounding in the genesis of "spontaneous" murine amyloidosis. Am J Pathol 1972, 67:555-567

34. Bittner RE, Anderson LV, Burkhardt E, Bashir R, Vafiadaki E, Ivanova S, Raffelsberger T, Maerk I, Hoger H, Jung M, Karbasiyan M, Storch M, Lassmann H, Moss JA, Davison K, Harrison R, Bushby KM, Reis A: Dysferlin deletion in SJL mice (SJL-Dysf) defines a natural model for limb girdle muscular dystrophy 2B. Nat Genet 1999, 23:141-142

35. Seabra AF, Mendonca DM, Goring HH, Thomis MA, Maia JA: Genetic and environmental factors in familial clustering in physical activity. Eur J Epidemiol 2008, 23:205-211

36. Milner LC, Crabbe JC: Three murine anxiety models: results from multiple inbred strain comparisons. Genes Brain Behav 2008, 7:496-505

37. Yu JG, Malm C, Thornell LE: Eccentric contractions leading to DOMS do not cause loss of desmin nor fibre necrosis in human muscle. Histochem Cell Biol 2002, 118:29-34

38. Costa A, Orosz Z, Apor P, Csaba N, Siamilis S, Csende Z, Racz L, Tihanyi J: Impact of repeated bouts of eccentric exercise on sarcolemma disruption in human skeletal muscle. Acta Physiol Hung 2009, 96:189-202

39. Roche JA, Lovering RM, Roche R, Ru LW, Reed PW, Bloch RJ: Extensive mononuclear infiltration and myogenesis characterize recovery of dysferlin-null skeletal muscle from contraction-induced injuries. Am J Physiol Cell Physiol 2010, 298:C298-C312

40. Barthélémy F, Wein N, Krahn M, Lévy N, Bartoli M: Translational research and therapeutic perspective in dysferlinopathies. Mol Med 2011, 17:875-882 